\title{
Positive Psychology and Digital Games: The Role of Emotions and Psychological Flow in Serious Games Development
}

\author{
Andreas Alexiou ${ }^{1}$, Michaéla Schippers ${ }^{1}$, Ilan Oshri ${ }^{2}$ \\ ${ }^{1}$ RSM, Erasmus University, Rotterdam, The Netherlands \\ ${ }^{2}$ School of Business and Economics, Loughborough University, Loughborough, UK \\ Email: aalexiou@rsm.nl
}

Received October $1^{\text {st }}$, 2012; revised November $5^{\text {th }}$, 2012; accepted December $1^{\text {st }}, 2012$

\begin{abstract}
In this paper we will discuss how positive psychology can contribute to the design of digital games and in particular training applications like Serious Games. While digital games have been known for their ability to deeply immerse users, stimulate the senses and tap into a broad range of emotions, it has proven rather challenging to use them as a vehicle for pedagogy. Relevant research is still at its infancy and many of the mechanisms that foster knowledge creation and enhance learning need to be mapped out before scripted in the game. The theory of psychological flow and the role of positive emotions in broadening people's thought-action repertoires bring some practical insights and pave the path for tackling some important design questions. Yet there are still major challenges and uncharted waters to be explored in order for the technology to deliver what has been promised.
\end{abstract}

Keywords: Positive Psychology; Flow; Serious Games; Positive Emotions; Digital Games

\section{Introduction}

Since the turn of the millennium positive psychology has become the umbrella framework for all scholars interested in the conditions and processes that contribute to the overall wellbeing and optimal functioning of people, groups and institutions (Gable \& Haidt, 2005). By focusing in the human virtues and character strengths (Seligman et al., 2005; Sheldon \& King, 2001), it aims to explore the mechanisms and conditions that lead to personal thriving and ultimately, happiness (for a review see Schippers \& Hogenes, 2011). A major component of personal development is the process of learning with its quintessence being the virtue of wisdom and constructive knowledge.

While young children have an intrinsic curiosity and love for learning, as they grow up and get introduced to formal education, "motivational deficits" begin to appear that increase steadily as children progress through school (Cordova \& Lepper, 1996). One main cause for this is the pedagogical practice that Brunner (1962, 1966) identified as decontextualization of instruction presenting new material in its most abstract or decontextualized form, hoping to promote a generalization of that learning (Cordova \& Lepper, 1996). This can be counteracted by playful experiential learning. Digital games are often immersive in nature and unleash the creativity, imagination and curiosity of the participants (e.g. Habgood et al., 2005; Hoffman \& Nadelson, 2009; Jennett et al., 2008; Thomas \& Brown, 2007). The above qualities of digital games have sparked a widespread interest towards the "marriage" of learning and play, in an attempt to produce a more engaging and enjoyable learning experience.

In the forefront of these developments is the blend of pedagogy with information technology and digital game elements (e.g. Garris et al., 2002; Gee, 2003; Prensky, 2003). Bearing the oxymoron name "Serious Games", these software applications aspire to bring into the world of learning, those elements of digital games that stimulate, immerse and engage players (for a review see Susi, Johannesson, \& Backlund, 2007). Despite existing skepticism and limited hard evidence on the effectiveness of this technology, the Serious Games industry has enjoyed exponential growth and is projected to expand to $€ 10$ billion by 2015 (IDATE, 2010).

The main motor behind this widespread interest are the inherent qualities of digital games. While well known for generating player engagement (Reeves \& Read, 2009), digital games also have the ability to provide players with control over scenarios; "emulate the real world and provide opportunities to train with some realism but out of harm's way" (Alexander et al., 2005); even build stronger social bonds, and lead to more active social networks by generating pro-social emotions (McGonigal, 2011).

However the blending of pedagogy activities that educate and instruct with entertainment poses serious challenges for designers and more often than not produces dubious results. With relevant research still at its infancy (Hays, 2005; Ke, 2009) positive psychology can provide significant insights on the processes and mechanisms that promote engagement as well as the role of soft factors like emotions and human energy on the ability to learn and generate knowledge.

\section{The Essence of Digital Games}

According to Zimmerman \& Salen, (2003: p. 80) “A game is a system in which players engage in an artificial conflict defined by rules, that results in a quantifiable outcome”. The above definition provides us with four primary elements of games: First, the artificiality is a defining characteristic of games. Game play presupposes the existence of a "magic circle", a place in space and time where participants enter or even create when the game begins (Zimmerman \& Salen, 2003: p. 95). According to Huizinga, (1955: p. 10) these are all "temporary 
worlds within the ordinary world, dedicated to the performance of an act apart". Fantasy, which is a driver for motivation, is therefore an important element within the act of play. Second, conflict suggests that games embody a contest of powers. The conflict could be between players or between players and the computer and presupposes the existence of rules. Third, rules exist to constrain behavior and provide a structure for the emerging act of play while they define the challenge and difficulty of the game. Finally, the artificial conflict is typically followed by closure (the end of the game) in the form of a quantifiable outcome that defines the winner or acts a measurement of performance (score points).

The above ludic nature of games often coexists with a layer of narrative. Be that abstract, minimal or complex, narrative aims to immerse the player in the game, stimulate fantasy and create emotional tension. In the case of digital games in particular, the narrative of the game is substantially enhanced by the use of visual (3D graphics) and aural (music, sound effects) elements that provide the player with sensory stimuli. The role of visual/aural aesthetics in creating the desired feeling of immersion has been already highlighted; in terms of visual aesthetics "the prototypical aesthetic experience is one in which attention is firmly fixed upon the components of a visual pattern, excludes the awareness of other objects or events, is dominated by intense feelings or emotions and is integrated and coherent" (Kubovy, 2000 cited in El-Nasr et al., 2007). On the other hand music and sound effects besides enriching the game-worlds and assisting player navigation are also important for the semantic operations of games by invoking "cognitive associations between types of music and interpretations of causality, physicality and character" (Whalen, 2004). The interplay between aesthetics, fantasy and challenge provides a holistic experience that energizes, immerses and often leads players to a state of flow. According to Csikszentmihalyi "games are obvious flow activities, and play is the flow experience par excellence” (1975: pp. 36-37).

Unfortunately, while the many unique advantages of digital games have already been highlighted and their potential as learning tools widely discussed (e.g. Prensky, 2003; de Freitas, 2006), we still lack knowledge about the underlying mechanisms through which these components can enhance the learning ability of players as well as the expert knowledge of how to script desired outcomes like creativity, curiosity, imagination or intrinsic motivation in the game. The theory of flow and existing research on positive emotions are two literature streams that have already attracted the attention of game designers and contribute towards this end.

\section{The Theory of Flow}

The construct of psychological flow that describes "the holistic sensation that people feel when they act with total involvement” (Csikszentmihalyi, 1975: p. 31), stresses out the role of optimal challenge in achieving such deep levels of immersion/engagement. According to the theory of flow two criteria need to be satisfied for an individual to experience flow: 1) the activity must provide with optimal challenge-the perceived level of ability must be in balance with the perceived challenges 2) the perceived levels of challenge and skill must be high. In this sense flow represents an optimum. In suboptimum situations, high skill coupled with low challenge results in boredom while low skill and high challenge results in anxiety and frustration. In the game environment, adjustable levels of difficulty and a "leveling system"- - how players advance their abilities and power up-are typically implemented in order to achieve this optimal state. There are two ways for the game difficulty to be adjusted. Either the player chooses their skill level (e.g. novice, experienced or expert) and the game adjusts to their choice or the game tracks down the player's performance and choice patterns and adjusts the game-world difficulty level to the player's skill. The mere existence of an adjustable difficulty level however is not enough to guarantee engagement or flow. There are many cases where games fail to confer the required sense of character growth that is inherent to the state of flow. Increasing in a more or less symmetrical way the variables of the game (e.g. weapon damage VS opponent's shield endurance) does not have the same effect as constantly expanding one's repertoire of actions, abilities and gear for achieving the increasingly more difficult objectives.

A typical example of digital games where the leveling system plays a central role, are Role Playing Games (RPGs). As players progress and become more experienced they have a chance to develop their characters' abilities and strengths through a "level-up" process and upgrade their gear so as to cope with the ever-increasing sophistication of riddles and enemies. The existence of challenges and foes that cannot be overcome unless the player levels up gives meaning to character growth. By having to choose among a multitude of abilities to unlock or enhance and gear to equip, they in essence develop their own approach/strategy in order to perform well in the game. As a result, RPGs allow players to advance a wider set of skills than the simple perceptual-motor skills that less sophisticated games require. The player experiences an in-game transformation, from ordinary person to extraordinary hero. The avatar's development resonates with the players' intrinsic need for growth and self-mastery. When implemented properly the gaming experience is absolutely engaging, enjoyable and rewarding.

The second contribution of the theory of flow is the identification of clear goals, clear and consistent feedback, and the feeling of control as important components for getting "in the zone”. Goals are fundamental to games as they define the outcome and a quantifiable outcome is part of the definition of games. What is also important besides the clarity of the goals is frequent feedback on how close the player is to achieving the goal. The introduction of sub-goals as a guide for achieving the ultimate objective can keep engagement and motivation levels high. A typical example of such a technique is the use of missions, quests and sub-quests. Exploring the use of sub-goals in order to provide the learner with the knowledge required to accomplish the higher objective might be a viable strategy for serious games designers.

Feedback is the cornerstone of reflection (Schippers, 2003). Reflection refers to "a generic term for those intellectual and affective activities in which individuals engage to explore their experiences in order to lead to new understandings and appreciation” (Boud et al., 1985). One mechanism of immediate feedback that also acts as a quantifier of player skill and experience, is the game score; an expression of the cybernetic process of play (Moore, 2011). Yet, feedback interventions have been historically found to have a variable effect on performance (Kluger \& DeNisi, 1996) therefore there is a need to further explore whether existing ways of providing feedback to the player are beneficial and how feedback influences posi- 
tively or negatively the occurrence of immersion and flow.

Control refers to the exercise of authority or the ability to regulate, direct, or command something (Garris et al., 2002). Existing research in control and motivation in a learning context shows that student control leads to higher motivation and enhances learning (Cordova \& Lepper, 1996). Games however while capable of providing extensive control over scenarios, strategies and decisions to the player, should at the same constrain the player's behavior through the existence of rules. That generates a conflict where the designer struggles between degrees of freedom-that would stimulate the creativity of players- and restraining rules - that would keep the challenge high and give structure to the act of play.

\section{Positive Affect and Emotions}

According to Järvinen (2001, cited in Parikka \& Suominen, 2006), the gaming situation is primarily an aesthetic situation of certain percepts, affects and emotions that the game produces for the player. Games are "imbued with the rhetorical strategies of affect” (Calleja, 2007) and can tap into a broad range of emotions and player experiences through the use of rich characters, nuanced gameplay, complex social networks, and interactive stories (Squire, 2002). Games can generate emotions ranging from joy, courage and bliss to anger, agony or even horror. The existence of very commercially successful titles at both sides of the continuum indicates that players find them equally entertaining or "fun". However in the case of Serious Games delivering enjoyment may be sought after but is not the basis for their existence. There is a need therefore for evaluating which subsets of emotions or states of affect are more closely related to learning outcomes and personal development and how can corresponding stimulants find their way into game design.

Emotions can be conceptualized as "multicomponent response tendencies that unfold over relatively short time spans" (Fredrickson, 2001). This means that emotions are linked with what emotion theorists call "specific action tendencies". This concept describes how different discreet emotions invoke corresponding actions/responses. Joy in particular has been found to invoke the urge to play. Playfulness allows for safe experimentation and during the act of play individuals build enduring social bonds (e.g. Lee, 1983) and intellectual resources by boosting creativity (Sherrod \& Singer, 1989) and fueling brain development, especially in younger ages (Panksepp, 1998). In the same way intrinsic interest creates an urge for exploration, openness to new experiences and information that naturally lead to personal growth.

According to Fredrickson (2001), "certain discrete positive emotions-including joy, interest, contentment, pride, and love-although phenomenologically distinct, all share the ability to broaden people's momentary thought-action repertoires and build their enduring personal resources, ranging from physical and intellectual resources to social and psychological resources”. The expanded repertoire of thoughts and actions enables a person to come up with more ideas further enhancing ingenuity (Fredrickson \& Branigan, 2005; Isen, 2000).

Positive emotions and states of affect seem to enhance processes vital for learning but the role of negative emotions remains ambiguous. While generally a happy person is more prone to creative and exploratory behavior (Huy, 1999), in the case of failure, jealousy, envy, a shattered self-esteem and self-sacrifice, can act as motivators for re-engaging in the act of gaming to pursue new events and more excitement (Mortensen, 2002). Additionally, the theory of flow informs us that feelings of enjoyment, accomplishment and satisfaction typically occur in retrospect as all concentration is focused on the task during actual engagement (Csikszentmihalyi, 1990). This raises interesting questions regarding the necessity of an optimal blend of positive and negative feelings (like agitation, tension) during the gaming experience. The method of "tension and release" that is central in many forms of art for example serves such a purpose. Tension is present in forms of art as a means for creating emotional hooks and games are especially good at delivering that feeling of being on edge. A challenge for game developers is therefore to manage that very player tension. The dynamism between the two phases works as a catharsis for the player; "the heightened feeling of triumph is an emotional response following a period of particularly heightened tension" (Rose, 2010). Yet there is no evidence to our knowledge on how such a mechanism would influence learning and the subprocesses of it.

\section{Personality and Learning Styles}

While most of the previous discussion focused primarily on identifying the antecedents and psychological mechanisms behind flow, enjoyment, or creativity and how they can be mapped out and incorporated in game design, it is equally important to consider what distinguishes certain individuals more prone to such states or emotions than others. In the case of flow, it has been reported that not all individuals are equally capable of experiencing the growth-enhancing state of flow frequently or intensely (e.g. Lefevre, 1988). According to Csikszentmihalyi, $(1975,1990,1997)$ individuals who perform activities for their own sake rather than trying to achieve an external goal are considered to have an autotelic personality and are more inclined towards experiencing flow than others. Composed out of the two Greek roots auto (self) and telos (goal) autotelic personalities pursue and exhibit high levels of intrinsic motivation in their daily activities and they tend to pursue activities that satisfy their internal needs. Despite its centrality in the theory of flow however, the autotelic personality has received limited attentions by positive psychology scholars (Asakawa, 2004).

Personality can also determine the learning styles adopted by individuals (Kolb, 1984). There is empirical evidence that learning styles are related to educational involvement, motivation (Honey \& Mumford, 1992), and student performance (Holley \& Jenkins, 1993; Okebukola, 1986; Roach et al., 1993). The classification of learning styles springs from Kolb's (1984) Experiential Learning Theory which considers the creation of knowledge as a combination of grasping and transforming experience (ibid. p. 41). The four phases in this process are: concrete experience; reflective observation; abstract conceptualization and active experimentation. Based on the reliance of an individual on any of the above learning modes we can identify different learning styles (strategies). Experiential learning theory is a model of human knowledge where knowledge specialties are mapped by their relative emphasis on the two dimensions of concreteness versus abstractness and action versus reflection (Boyatzis \& Kolb, 1995). The combinations of the above specialties introduce different learning types (profiles) namely: 
- Convergers: abstract conceptualization + active experimenttation. They are good at making practical applications of ideas and using deductive reasoning to solve problems.

- Divergers: concrete experience + reflective observation. They are imaginative and are good at coming up with ideas and seeing things from different perspectives.

- Assimilators: abstract conceptualization + reflective observation. They are capable of creating theoretical models by means of inductive reasoning.

- Accommodators: concrete experience + active experimenttation. They are good at actively engaging with the world and actually doing things instead of merely reading about and studying them.

The above short discussion shows the importance of considering the moderating effect of personality when exploring the relationship between positive psychology concepts and learning. Given that a particular game setup will not be universally compatible with the expectations and dispositions of all players there is a need for incorporating in the game design mechanisms for the game to adapt to the payer's choices and allow her to use different strategies for creating and assimilating knowledge.

\section{Conclusion}

Digital games are designed experiences where the "cognitive, emotional, and kinaesthetic feedback loop that is formed between the game process and the player" can significantly affect players' moods and emotional states (Calleja, 2007). In combination with the technology's ability to create accurate spatial, situational or mechanical simulations, digital games can be transformed into highly engaging and sophisticated learning/ training tools. Incorporating pedagogy in the gaming experience poses significant challenges and positive psychology holds certain keys to tackle them.

Exploring the antecedents and processes that invoke intrinsic motivation and lead to engagement and flow, understanding how, why and under which conditions positive emotions enhance the learning ability, investigating the mechanism through which curiosity and creativity is sparked and retained, how personality moderates these effects as well as the role of pleasure and enjoyment in learning and retaining knowledge are only some of the areas that could help us fine-tune games so as to resonate with the innate needs of individuals for self-development and personal growth.

The theory of flow has already provided developers with important insight on some aspects of their design such as the importance of balancing challenges to player skill, the existence of clearly defined goals, and the provision of immediate feedback (e.g. Carr et al., 2006; Juul, 2005; King \& Krzywinska, 2006). At the same time the positive emotions that are associated with the energetic activation of individuals have been shown to broaden the available thought-action repertoire that a person has during any given activity (Fredrickson, 2001; Quinn, et al., 2012; Schippers \& Hogenes, 2011).

Unfortunately research linking specific positive emotions to corresponding action tendencies is scarce (Fredrickson \& Levenson, 1998) as is the literature regarding the moderating effects of the autotelic personality and user enjoyment on learning during game-play. Maybe it is not possible to directly script flow, positive affect or creativity and open-mindedness in the game but relevant research can enlighten us regarding the background mechanisms and relationships that can be taken into consideration while developing such applications. Positive psychology could contribute to the advancement of a medium and technology that will not only enhance traditional methods of training/education but also revolutionize a "representational form that could help us understand the reality that surrounds us and, above all, what it means to be human” (Frasca, 2001).

\section{Acknowledgements}

Our research is funded under the EU FP7 Marie Curie Research Training Network and is part of the Management of Emerging Technologies for Economic Impact project. We would like to thank Prof. Dr. Ing. Frans Van Den Bosch for his insightful comments and support.

\section{REFERENCES}

Alexander, A. L., Brunyé, T., Sidman, J., \& Weil, S. A. (2005). From gaming to training: A review of studies on fidelity, immersion, presence, and buy-in and their effects on transfer in pc-based simulations and games. URL (last checked 30 September 2012).

http://www.aptima.com/publications/2005_Alexander_Bruyne_Sidm an_Weil.pdf

Asakawa, K. (2004). Flow experience and autotelic personality in Japanese college students: How do they experience challenges in daily life? Journal of Happiness Studies, 5, 123-154. doi:10.1023/B:JOHS.0000035915.97836.89

Boud, D., Keogh, R., \& Walker, D. (1985). Reflection: Turning experience into learning. Abington: Rutledge Falmer.

Boyatzis, R. E., \& Kolb, D. A. (1995). From learning styles to learning skills: The executive skills profile. Journal of Managerial Psychology, 10, 3-17. doi:10.1108/02683949510085938

Bruner, J. (1962). On Knowing: Essays for the left hand. Cambridge, MA: Belknap Press of Harvard University Press.

Bruner, J. (1966). Toward a theory of instruction. Cambridge, MA: Harvard University Press.

Calleja, G. (2007). Digital game involvement: A conceptual model. Games and Culture, 2, 236-260. doi:10.1177/1555412007306206

Carr, D., Buckingham, D., Burn, A., \& Schott, G. (2006). Computer games: Text, narrative and play. Cambridge: Polity Press.

Cordova, D. I., \& Lepper, M. R. (1996). Intrinsic motivation and the process of learning: Beneficial effects of contextualization, personalization, and choice. Journal of Educational Psychology, 88, 715-730. doi:10.1037/0022-0663.88.4.715

Csikszentmihalyi, M. (1975). Beyond boredom and anxiety: Experiencing flow in work and play. San Fransisco: Jossey-Bass.

Csikszentmihalyi, M. (1990). Flow: The psychology of optimal experience. New York, NY: Harper-Perennial.

Csikszentmihalyi, M. (1997). Finding flow: The psychology of engagement with everyday life. New York, NY: Basic Books.

De Freitas S. I. (2006): Using games and simulations for supporting learning. Learning, Media and Technology, 31, 343-358.

El-Nasr, M. S., Niedenthal, S., Knez, I., Almeida, P., \& Zupko, J. (2007). Dynamic lighting for tension in games. Game Studies, 7, URL (last checked 30 September 2012).

http://gamestudies.org/0701/articles/elnasr_niedenthal_knez_almeida _zupko

Frasca, G. (2001). Videogames of the oppressed: Videogames as a means for critical thinking and debate. MA. Thesis, Atlata: Georgia Institute of Technology.

Fredrickson, B. (2001). The role of positive emotions in positive psychology: The broaden-and-build theory of positive emotions. American Psychologist, 56, 218-226.

Fredrickson, B. L., \& Branigan, C. (2005). Positive emotions broaden the scope of attention and thought-action repertoires. Cognition \& Emotion, 19, 313-332. doi:10.1080/02699930441000238

Fredrickson, B. L., \& Levenson, R. W. (1998). Positive emotions speed 
recovery from the cardiovascular sequelae of negative emotions. Cognition \& Emotion, 12, 191-220. doi:10.1080/026999398379718

Gable, S. L., \& Haidt, J. (2005). What (and why) is positive psychology? Review of General Psychology, 9, 103-110. doi:10.1037/1089-2680.9.2.103

Garris, R., Ahlers, R., \& Driskell, J. E. (2002). Games, motivation, and learning: A research and practice model. Simulation \& Gaming, 33, 441-467. doi:10.1177/1046878102238607

Gee, J. P. (2003). What video games have to teach us about learning and literacy. Computers in Entertainment, 1, 20-20. doi:10.1145/950566.950595

Habgood, M. P. J., Ainsworth, S. E., \& Benford, S. (2005). Endogenous fantasy and learning in digital games. Simulation \& Gaming, 36, 483-498.

Hays, R. T. (2005). The effectiveness of instructional games: A literature review and discussion. Orlando, FL: Naval Air Warfare Center.

Hoffman B., \& Nadelson, L. (2009). Motivational engagement and video gaming: A mixed methods study. Educational Technology Research and Development, 58, 245-270.

Holley, J. H., \& Jenkins, E. K. (1993). The relationship between student learning style and performance on various test question formats. Journal of Education for Business, 68, 301-308.

Honey, P., \& Mumford, A. (1992). The manual of learning styles. Berkshire: Peter Honey Publications.

Huizinga, J. (1955). Homo ludens: A study of the play-element in culture. Boston, MA: The Beacon Press.

Huy, Q. (1999). Emotional capability, emotional intelligence, and radical change. Academy of Management review, 24, 325-345.

IDATE Consulting \& Research (2010). Serious games a 10 billion euro market in 2015. URL (last checked 30 September 2012). www.idate-research.com

Isen, A. M. (2000). Ch. 33: Some ways in which positive affect and influences decision making. Handbook of emotions (3rd ed., pp. 417-435). New York, NY: Guilford Press.

Jennet, C., Cox, A., Cairns, P., Dhoparee, S., Epps, A., Tijs, T., \& Walton, A. (2008). Measuring and defining the experience of immersion in games. International Journal of Human-Computer Studies, 66, 641-661.

Juul, J. (2005). Half-real: Video games between real rules and fictional worlds. Cambridge, MA: The MIT Press.

Järvinen, A. (2001). Quake ${ }^{\circledR}$ goes the environment: Game aesthetics and archaeologies. Digital Creativity, 12, 67-76. doi:10.1076/digc.12.2.67.6865

Ke, F. (2009). Ch. 1: A qualitative meta-analysis of computer games as learning tools. Handbook of Research on Effective Electronic Gaming in Education (pp. 1-32). London: IGI Global.

King, G., \& Krzywinska, T. (2006). Tomb raiders and space invaders: Videogame forms and contexts. New York, NY: I.B.Tauris.

Kluger, A., \& DeNisi, A. (1996). The effects of feedback interventions on performance: A historical review, a meta-analysis, and a preliminary feedback intervention theory. Psychological Bulletin, 2, 254284. doi:10.1037/0033-2909.119.2.254

Kolb, D. A. (1984). Experiential learning: Experience as the source of learning and development. New Jersey: Prentice Hall.

Kubovy, M. (2000). Visual aesthetics. Encyclopedia of Psychology. New York, NY: Oxford University Press.

Lee, P. (1983). Play as a means for developing relationships. Primate Social Relationships (pp. 82-89). Oxford: Blackwell.

Lefevre, F. (1988). Ch. 18: Flow and the quality of experience during work and leisure. Optimal Experience: Psychological Studies of Flow in Consciousness (pp. 307-318). Cambridge: Cambridge University Press. doi:10.1017/CBO9780511621956.018

McGonigal, J. (2011). Reality is broken: Why games make us better and how they can change the world. New York: Penguin Press.

Moore, C. (2011). Hats of affect: A study of affect, achievements and hats in team fortress 2. Game Studies, 11. URL (last checked 30 September 2012). http://gamestudies.org/1101/articles/moore

Mortensen, T. (2002). Playing with players. Game Studies, 2. URL (last checked 30 September 2012).

http://www.gamestudies.org/0102/mortensen/

Okebukola, P. A. (1986). The influence of preferred learning styles on cooperative learning in science. Science Education, 70, 509-517. doi:10.1002/sce.3730700505

Panksepp, J. (1998). Attention deficit hyperactivity disorders, psychostimulants, and intolerance of childhood playfulness: A tragedy in the making? Current Directions in Psychological Science, 7, 91-98. doi:10.1111/1467-8721.ep10774709

Parikka, J., \& Suominen, J. (2006). Victorian snakes? Towards a cultural history of mobile games and the experience of movement. Game Studies, 6. URL (last checked 30 September 2012). http://gamestudies.org/0601/articles/parikka_suominen

Prensky, M. (2003). Digital game-based learning. Computers in Entertainment, 1, 21. doi:10.1145/950566.950596

Quinn, R., Spreitzer, G., \& Fu Lam, C. (2012). Building a sustainable model of human energy in organizations: Exploring the critical role of resources. The Academy of Management Annals, 6, 337-396. doi:10.1080/19416520.2012.676762

Reeves, B., \& Read, J. L. (2009). Total engagement: Using games and virtual worlds to change the way people work and businesses compete. Boston, MA: Harvard Business School Press.

Roach, S. S., Johnston, M. W., \& Hair, J. F. (1993). An exploratory examination of teaching styles currently employed in marketing education: Developing a typology and its implications for marketing students. Journal of Marketing Education, 15, 32-38. doi:10.1177/027347539301500305

Rose, J. (2010). Addressing conflict: Tension and release in games. URL (last checked 30 September 2012).

http://www.gamasutra.com/view/feature/134313/addressing_conflict _tension_and_.php?print $=1$

Seligman, Martin, E. P., Steen, T. A., Park, N., \& Peterson, C. (2005). Positive psychology progress: Empirical validation of interventions. American psychologist, 60, 410-421. doi:10.1037/0003-066X.55.1.5

Sheldon, K. M., \& King, L. (2001). Why positive psychology is necessary. American Psychologist, 56, 216-217. doi:10.1037/0003-066X.56.3.216

Sherrod, L., \& Singer, J. (1989). The development of make-believe play. Sports, games and play (pp. 1-38). Hillsdale, NJ: Erlbaum.

Schippers, M. C. (2003). Reflexivity in teams. Dissertation, Amsterdam: Free University.

Shippers, M. C., \& Hogenes R. (2011). Energy management of people in organizations: A review and research agenda. Journal of Business Psychology, 26, 193-203. doi:10.1007/s10869-011-9217-6

Squire, K. (2002). Cultural framing of computer/video games. Game Studies, 2, 90. URL (last checked 30 September 2012). http://gamestudies.org/0102/squire/

Susi, T., Johannesson, M., \& Backlund, P. (2007). Serious games-An overview. Skövde: School of Humanities and Informatics, University of Skövde.

Thomas, D., \& Brown J. S. (2007). The play of imagination: Extending the literary mind. Games and Culture, 2, 149-172.

Whalen, Z. (2004). Play along-An approach to videogame music. Game studies, 4. URL (last checked 30 September 2012). http://www.gamestudies.org/0401/whalen/

Zimmerman, E., \& Salen, K. (2003). Rules of play: Game design fundamentals. Boston, MA: MIT Press. 